\title{
O uso das TIC no apoio a estudantes com Necessidades Educativas Especiais em
}

\author{
Manaus, Amazónia
}

\section{The use of ICT to support students with special educational needs in Manaus,}

\author{
Amazon \\ Aldenei Barros*, Maria João Gomes**, Anabela Cruz Santos** \\ *Secretaria de Educação e Qualidade do Ensino - Manaus, **Universidade do Minho
}

\begin{abstract}
Resumo
Este estudo teve por finalidade caracterizar o uso das tecnologias de informação e comunicação (TIC) no apoio a estudantes com necessidades educativas especiais, identificando os fatores condicionantes do uso das TIC . Foi desenvolvido um questionário e aplicado a 100 professores do ensino médio, que exerciam funções docentes em cinco escolas da rede pública da cidade de Manaus, Brasil. Os resultados deste estudo indicam que: a) o uso do smartphone é superior nos professores com idades compreendidas entre os 31 a 40 anos, enquanto o uso do smartphone é menor entre os professores com idade acima de 50 anos, b) o uso dos recursos disponíveis pela escola aos alunos (internet), é superior no caso dos professores com idades entre os 31 a 40 anos do que em relação aos professores com idade acima de 50 anos, c) os professores com idade entre os 41 a 50 anos são os que utilizam mais o tablet com os alunos, d) a utilização do computador como recurso didático com os alunos é superior nos professores que possuem pós-graduação, do que em relação aos professores que possuem outro tipo de formação, e e) a utilização do netbook em práticas pedagógicas é superior nos professores que têm até 20 anos de tempo de serviço, em relação aos restantes grupos. Do estudo obteve-se um quadro dos fatores que condicionam o uso das tecnologias de informação e comunicação por parte dos professores no apoio aos estudantes com necessidades educativas especiais, desse modo contribuindo para a fundamentação de medidas a tomar por parte das entidades educativas.

Palabras-chave: Tecnologias de Informação e Comunicação, Necessidades Educativas Especiais, Inclusão digital, Ensino Médio
\end{abstract}

\footnotetext{
Abstract

This study aimed to characterize the use of information and communication technologies (ICT) in the support of students with special educational needs, identifying the factors conditioning the use of ICT. A questionnaire was developed and applied to 100 high school teachers, who were teaching at five schools in the city of Manaus, Brazil. The results of this study indicate that: a) the use of the smartphone is superior in the teachers between the ages of 31 and 40 years, while the use of the smartphone is smaller among teachers over the age of 50, b) the use of resources Available to students (internet), is higher for teachers aged 31-40 than for teachers over 50, c) teachers aged 41-50 are
}

That use the tablet more with the students, d) the use of the computer as a didactic resource with the students is superior in the professors that have postgraduate, than in relation to the teachers who have other type of training, and e) the use of the netbook In pedagogical practices is superior in teachers who have up to 20 years of service time, in relation to the other groups. that condition the use of the information and communication technologies by the teachers in the support to the students with special educational needs, in this way contributing to the foundation of measures to be taken by the educational entities.

Keywords: Information and Communication Technologies, Special Educational Needs, Digital Inclusion, Secondary Education

\section{Introdução}

Este texto visa divulgar resultados de uma pesquisa a respeito dos fatores condicionantes do uso das Tecnologias de Informação e Comunicação, no atendimento a alunos com NEE de escolas públicas da cidade de Manaus - Amazonas - Brasil, por parte dos professores do Ensino Médio.

O Plano Nacional de Educação, publicado em 25 de junho de 2014, como Lei $\mathrm{n}^{\circ} 13005$ constituiu a primeira iniciativa legal de se garantir a formação incial de continuada de professores para o emprego das Tecnologias de Informação e Comunicação (TIC) em contexto escolar. Campos (2010), reportando-se ao Brasil, salienta que "a formação inicial de professores ensaia passos na caminhada de implementação das diretrizes curriculares, e a formação continuada é ainda muito tímida, faltando à definição de programas que atenda as carências dos professores da escola real" (Campos, 2010, p.87). Por outro lado, o Brasil tem vindo a reforçar as suas políticas de inclusão social das pessoas com necessidades especiais (PNE), nomeadamente promovendo a integração dos alunos com necessidades educativas especiais nas escolas regulares.

Promover a inclusão de pessoas com necessidades especiais em geral, e a inclusão dos alunos com necessidades educativas especiais, passa, forçosamente, por criar condições de acesso e uso das tecnologias de informação e comunicação (TIC) desde a infância. Nesse 
sentido, as escolas e os professores não podem ficar alheias a este processo. Por esta razão, importa conhecer quais os fatores condicionantes do uso das tecnologias de informação e comunicação por professores do ensino médio no apoio a estudantes com necessidades educativas especiais, razão pela qual se levou a cabo esta pesquisa.

Percorrer este caminho exige que o papel do professor quanto ao emprego das TIC seja repensado, pois no entender da UNESCO, "intervenções baseadas em TIC também precisam se encaixar em outros contextos do ambiente de aprendizagem, incluindo o papel do professor" (UNESCO, 2013, p.26). Capacitar o professor para a utilização das TIC no contexto educativo é uma premissa importante neste processo, pois "neste contexto, o fator crítico será a capacidade dos professores em utilizar as TIC para se envolver efetivamente com as pessoas que têm uma ampla gama de deficiência, assumindo que eles têm sido capazes de reconhecer que as dificuldades exigem intervenções educativas especiais" (UNESCO, 2013, p.26).

De acordo com Santarosa (1997) O emprego das TIC em apoio a pessoas com Necessidades Educativas Especiais (NEE) ocorre em duas dimensões. Na primeira elas podem ser utilizadas como meios de apoio à comunicação (por exemplo, no apoio às dificuldades ao nível da linguagem) e à aprendizagem, constituindo-se como elementos de suporte aos processos de inclusão de alunos com NEE, tanto a nível social quanto educacional, neste caso funcionando como tecnologias assistivas. $\mathrm{Na}$ segunda, as TIC podem ser empregadas como objeto de aprendizagem, quando o objetivo é que os alunos aprendam a utilizar as tecnologias, de forma a promover a inclusão digital destes alunos. Assim, as TIC podem ser elementos potenciadores da inclusão social das pessoas com necessidades especiais, quer evitando que estas fiquem excluídas do acesso aos recursos e potencialidades associados às TIC, evitando assim que se constituam como info-excluídos, quer dotando-as de competências de uso das TIC que lhes permitam ultrapassar algumas das suas limitações, facilitando a sua inclusão social.

Dentro desta perspectiva, as práticas pedagógicas contemporâneas devem programar a inclusão digital de pessoas com necessidades educativas especiais através do uso das tecnologias de informação e comunicação (TICs), facilitando o desenvolvimento da aprendizagem e ampliando seus direitos de cidadania através da inclusão digital.

No que se refere à inclusão digital de pessoas com NEE, Valle entende que as novas tecnologias de informação e comunicação fornecem um amplo espectro de inclusão.

Assim, esta pesquisa investigou, com base numa amostra de 100 professores, a utilização das TIC por parte dos professores da rede pública de ensino médio de Manaus, no seu trabalho com alunos com NEE, identificando fatores que podem condicionar essa utilização. Partiu-se de uma caracterização geral da experiência dos professores com turmas com alunos com NEE, identificou-se a formação dos professores no campo específico das NEE e das TIC com foco no apoio a alunos com NEE, caracterizou-se o tipo de recursos tecnológicos (hardware e software) que estão disponíveis aos professores da rede pública de ensino de Manaus nas escolas em que trabalham bem como o acesso que têm às mesmas a partir das suas casas e identificou-se o tipo de recursos tecnológicos que os professores da rede pública de ensino de Manaus utilizam com os seus alunos.

\section{Questão de investigação e objetivos do estudo}

Partindo do reconhecimento do potencial educativo das TIC e da responsabilidade das escolas e professores assegurarem a sua integração nas práticas escolares, nomeadamente em contextos que se pretendem inclusivos, assumiu-se como ponto de partida a necessidade de identificar os principais fatores condicionantes das práticas dos professores, no contexto da rede pública da cidade de Manaus, com foco nos professores do ensino médio que lidam com alunos com NEE. Assim, assumimos a seguinte questão de investigação:

Quais são os fatores condicionantes do uso das tecnologias de informação e comunicação por professores do ensino médio no apoio a estudantes com necessidades educativas especiais?

Subjacente à questão de investigação que acabamos de apresentar está um conjunto de objetivos que orientaram o processo de recolha de dados:

- Identificar que formação possuem os professores da rede pública de ensino médio de Manaus relativamente ao uso das tecnologias de informação e comunicação, em contexto pessoal e em contexto profissional.

Identificar que formação possuem os professores da rede pública de ensino médio de Manaus relativamente ao uso das tecnologias de informação e comunicação, em atividades de apoio a alunos com necessidades educativas especiais (NEE).

- Identificar que tipo de recursos tecnológicos (hardware e software) têm acesso os professores da rede pública de ensino de Manaus nas escolas em que trabalham.

- Identificar a existência de práticas pedagógicas com recurso às TIC desenvolvidas pelos professores da rede pública de ensino de Manaus que atuam com alunos que apresentam diferentes NEE.

\section{Caracterização dos participantes}

A pesquisa em lokus (de campo) foi realizada em 05 escolas de ensino médio, da rede estadual de ensino público da cidade de Manaus. Os sujeitos envolvidos na pesquisa foram cem (100) professores do Ensino Médio da rede estadual de ensino que possuíam, à data de recolha de dados ou nos 4 anos anteriores, alunos com NEEs em suas turmas regulares, no Ensino Médio. Todas as 5 escolas se integram na rede pública estadual da Coordenadoria 6 , nas adjacências do núcleo 3 , do bairro Cidade Nova 2, rede pública estadual de Manaus.

A amostra de sujeitos foi constituída por 52 sujeitos do género feminino e 38 sujeitos do género masculino, constituindo, respetivamente $52 \%$ e $48 \%$ dos sujeitos 
totais. Foram considerados 4 escalões etários, sendo que o escalão mais frequente corresponde aos sujeitos com idades entre os 41 e os 50 anos, com $36 \%$ dos sujeitos enquadrados nesta categoria. Entre os 31 e os 40 anos de idade enquadravam-se $30 \%$ dos professores, $24 \%$ entre os 20 e os 30 anos e $10 \%$ tinham mais de 50 anos de idade. No que concerne à formação acadêmica, constatou-se que a maioria dos sujeitos $(55 \%)$ possuía licenciatura, enquanto que $45 \%$ possuíam uma pósgraduação. Quanto à experiência profissional enquanto docentes, verificou-se que cerca de um quarto $(26 \%)$ dos docentes tem menos de 5 anos de serviço, sendo que $8 \%$ dos sujeitos tem mais de 25 anos de serviço.

\section{Instrumento de coleta de dados}

O instrumento de coleta de dados consistiu num questionário desenvolvido especificamente para esta pesquisa. As questões do questionário foram organizadas de acordo com seis dimensões de análise, tendo por base a questão de investigação e os objetivos do estudo e incluindo um total de 22 perguntas, essencialmente de resposta fechada:

- Caracterização biográfica/demográfica dos sujeitos - foram contempladas 4 questões: gênero, idade, formação acadêmica, e anos de serviço.

- $\quad$ Atividade profissional em turmas com alunos com necessidades educativas especiais - foram incluídas 2 questões: se o participante trabalha com alunos com NEE, tipos de casos de alunos com NEE.

- Formação profissional no âmbito das necessidades educativas especiais - foram incorporadas 3 questões: formação acadêmica no âmbito da Educação Especial, formação durante a graduação em educação especial e inclusão de alunos com NEE no ensino regular, formação a nível de pós-graduação ou formação continuada em educação especial e inclusão de alunos com NEE no ensino regular.

- $\quad$ Formação no âmbito da utilização das tecnologias de informação e comunicação foram incluídas 4 questões: formação acadêmica no âmbito do uso das tecnologias de informação e comunicação no ensino, formação durante a graduação em tecnologias da informação e comunicação no ensino, formação durante a pós-graduação ou formação continuada em tecnologias da informação e comunicação no ensino, formação de graduação ou continuada, onde fosse abordada a temática do uso das tecnologias de informação e comunicação no apoio a estudantes com NEE.

- Condições de acesso às tecnologias de informação e comunicação em casa - foram incluídas 3 questões: posse de equipamento de informática e de telecomunicações a nível pessoal, caso não possua computador, e caso possua computador mas não possua acesso à internet.

- Condições de acesso e uso das tecnologias de informação e comunicação - foram incluídas 5 questões: indicar quais os recursos didáticos que o professor utiliza em sua prática pedagógica, indicar quais os recursos existentes na escola para uso pelos professores, indicar quais os recursos existentes na escola para uso pelos alunos, indicar quais os recursos tecnológicos que o professor utilizou ou utiliza com seus alunos e indicar quais os recursos tecnológicos o professor utiliza com seus alunos com necessidades educativas especiais.

\section{Procedimentos de coleta de dados}

Devido às limitações da pesquisa em termos de recursos temporais, humanos e financeiros para uma pesquisa mais ampla, todas as escolas pesquisadas localizam-se no bairro Cidade Nova, na Zona Norte de Manaus.

As escolas pesquisadas pertencem à Coordenadoria Distrital de Educação 6, responsável pelas escolas da Zona Norte do Município de Manaus, conforme o mapa representado na Figura 1, onde se encontra destacado o bairro de número 51, Cidade Nova, no qual se localizam as escolas pesquisadas.

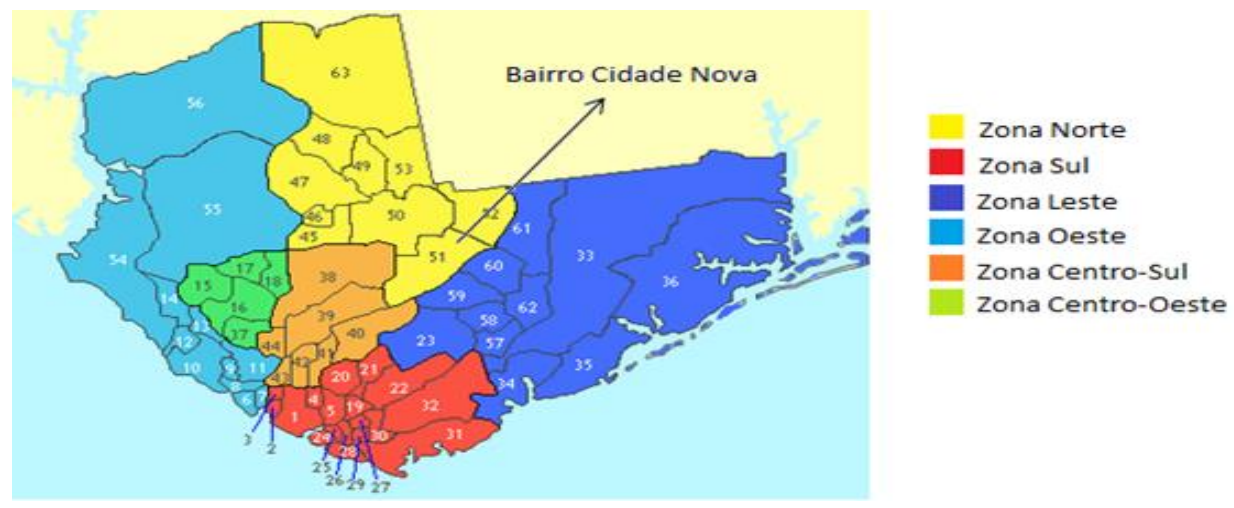

Figura 1 - Mapa dos bairros de Manaus. Fonte: Adaptado de http://pt.wikipedia.org

Tendo em vista a operacionalização da coleta de dados para a pesquisa, foram realizados contatos com os responsáveis pela gestão das Escolas de Ensino Médio a fim de obter dos mesmos a autorização para realizar a pesquisa com o corpo docente das respectivas escolas. Aos gestores de cada escola selecionada para a pesquisa, expôs-se detalhadamente os detalhes a respeito do Projeto de Pesquisa tendo sido apresentada a cada gestor a Carta de Anuência para a realização da pesquisa no estabelecimento de ensino sob sua administração, bem como o Termo de Consentimento Livre e Esclarecido (TCLE) a ser preenchido pelos docentes por ocasião da 
coleta de dados, e uma cópia do questionário a ser preenchido pelos docentes.

Após a obtenção da concordância dos respetivos gestores, iniciou-se o processo de coleta de dados junto dos professores. Foram realizadas diversas visitas às escolas até se ter conseguido obter 20 sujeitos, em cada uma das escolas, que cumprisse os requisitos estabelecidos e estivesse disponível para participar no estudo. Note-se que todos os sujeitos assinaram uma declaração de consentimento livre e esclarecido.

Os dados de natureza quantitativa foram objeto de tratamento estatístico. A análise estatística foi realizada com o uso do software IBM SPSS (Statistical Package for Social Sciences).

\section{Apresentação e análise de dados}

A apresentação dos dados está organizada em função das dimensões do questionário a que fizemos referência anteriormente. São aqui reportados os dados mais significativos que foram coletados.

Uma das questões colocadas aos professores consistia em identificar o tipo de casos de alunos com NEE com que já tinham lidado nas suas turmas. Apresentam-se as respostas dos professores no gráfico 1 a partir da qual se pode constatar que o tipo de deficiência com que maior número de professor já lidou corresponde a deficiência física (42\%) e deficiência intelectual (45\%), seguindo-se o contacto com alunos com deficiência auditiva (31\%), com deficiência visual (16\%) e múltiplas deficiências $(6 \%)$.

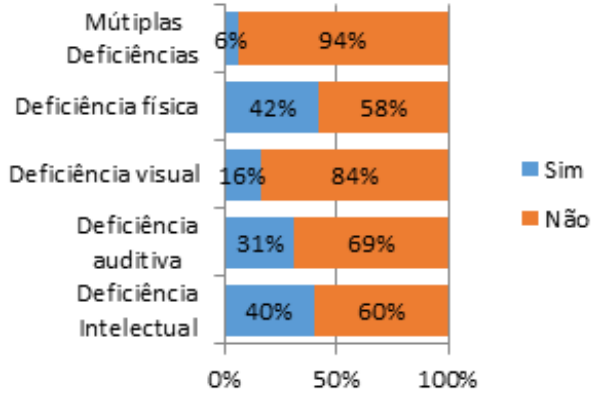

Gráfico 1 - Distribuição dos resultados obtidos referentes ao contacto com alunos com diferentes tipos de NEE.

Considerando que os sujeitos participantes no estudo eram professores que já tinham tido alunos com NEE integrados nas suas turmas, procurou-se identificar formação dos mesmos no domínio das NEE, tendo-se constatado que $89 \%$ destes professores não possuíam qualquer tipo de formação/grau acadêmico nesse âmbito (ver gráfico 2).

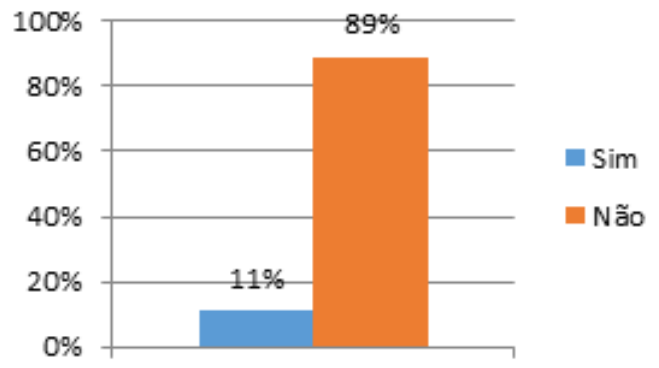

Gráfico 2 - Distribuição dos resultados obtidos no questionário aplicado, em função da formação/grau acadêmico em NEE.

Considerando a possibilidade de que os professores sem formação/grau académico específico em NEE pudessem ter algum tipo de formação nesse domínio obtida no contexto dos seus cursos de graduação ou em contextos e formação continuada, questionaram-se os professores sobre esse aspetos.

Os dados coletados indicam que $42 \%$ dos professores recebeu alguma formação no âmbito das NEE durante a sua graduação (ver gráfico 3 ), sendo que $4 \%$ teve mais do que uma oportunidade de formação nessa área, apesar da maioria dos professores não ter recebido qualquer formação nesse domínio (54\%). Contudo, um pequeno número.

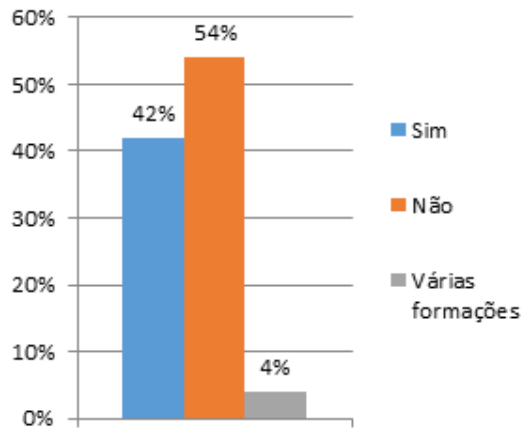

Gráfico 3 - Professores com formação em NEE obtida durante a graduação.

Quanto à formação de professores no campo das TIC contatou-se que $49 \%$ dos professores não teve qualquer formação em TIC durante os seus cursos de graduação, sendo que $48 \%$ dos participantes refere ter tido formação e $3 \%$ dos professores tiveram mais do que uma disciplina/formação em TIC durante a graduação (gráfico 4).

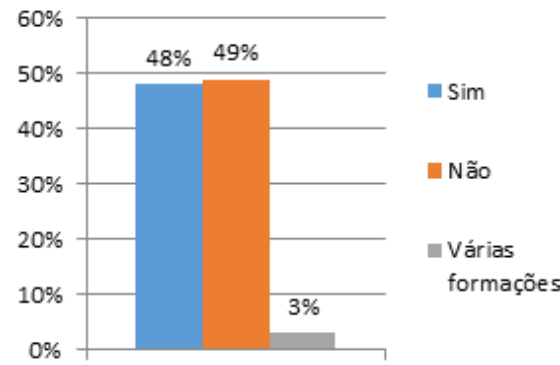

Gráfico 4 - Professores que cursaram disciplinas de formação em TIC no contexto das suas graduações.

Os dados indicam também que o $29 \%$ dos professores da amostra obteve formação em TIC em contexto de pós- 
graduação ou formação continuada, valor que nos parece baixo, face às condições de formação inicial bem como ao ritmo de evolução das TIC e da sua integração no cotidiano dos alunos (gráfico 5).

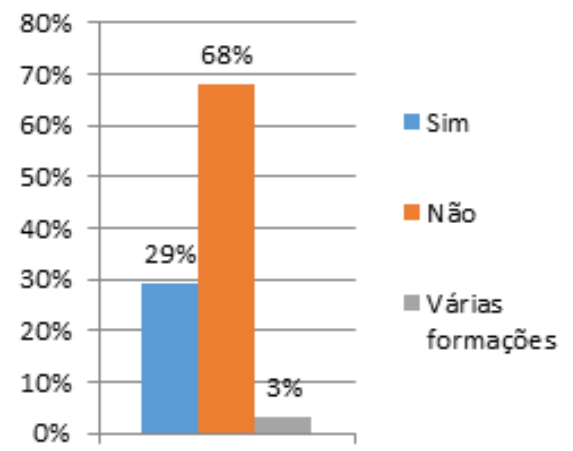

Gráfico 5 - Professores que cursaram formação em TIC no contexto de cursos de pós-graduação ou formação continuada.

No que respeita à existência de professores com formação em TIC direcionadas para o seu uso junto de alunos com NEE, o valor encontrado é ainda menor, com $19 \%$ de professores e referirem esse fato a que acresce $3 \%$ que referem ter frequentado várias formações nesse campo (ver gráfico 6).

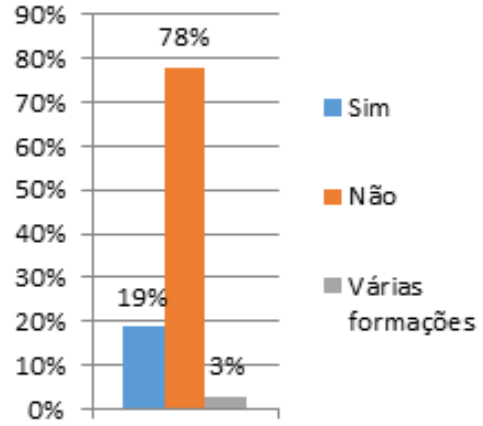

Gráfico 6 - Professores que frequentaram formação em TIC e NEE em contexto de pós-graduação ou formação continuada.

Recolheram-se também alguns dados relativamente às condições de posse de dispositivos tecnológicos e de acesso à Internet por parte dos professores inquiridos (ver gráfico 7). Em termos de posse de equipamento o notebook surge como sendo o mais comum (78\% afirma possuir notebook) sendo que apenas $13 \%$ dos participantes possui iPad/tablet.

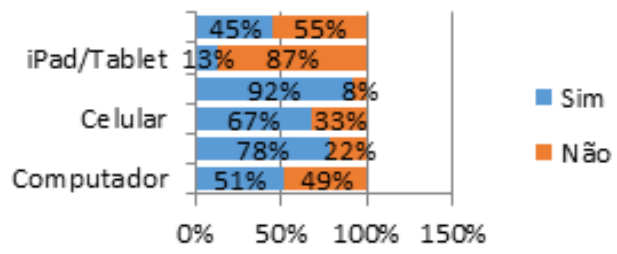

Gráfico 7 - Acesso, a partir de casa, a equipamento e internet por parte dos participantes.

Apenas 4\% do total de participantes (4 sujeitos) referiram não possuir nenhum tipo de computador sendo que $2 \%$ referiram não ter recursos para possuírem computador e $2 \%$ referiram não sentir necessidades de ter computador.
Procurou-se também identificar o tipo de recurso didático utilizado pelos professores nas suas práticas docentes de acordo com os dados representados no gráfico 8. Entre os recursos didáticos mais utilizados contabiliza-se o "data-show" (84\%), o notebook (71\%) e televisão/vídeos (74\%) e notebook (71\%). Alguns professores $(7 \%)$ referem explicitamente o uso de "software específico para NEE".

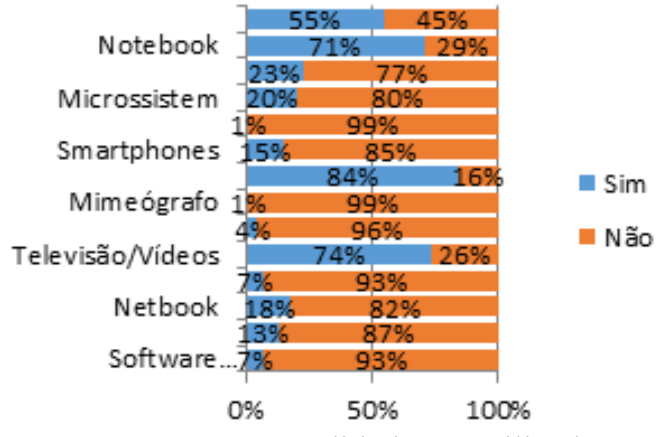

Gráfico 8 - Recursos didáticos utilizados pelos professores.

Também se identificou o tipo de recursos TIC disponíveis aos professores nas escolas encontram-se apresentados no gráfico 9. Registe-se que um número elevado de professores referem a existência de internet $(90 \%)$ e de computadores $(88 \%)$ na escola, sendo que o número de participantes que refere existência de tablets na escola é apenas de $4 \%$.

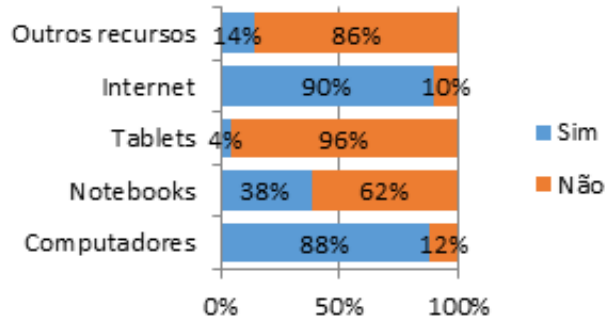

Gráfico 9 - Recursos TIC disponíveis aos professores 'nas escolas.

Os professores foram também inquiridos quanto aos recursos TIC disponíveis para uso pelos alunos nas escolas (ver gráfico 10). À semelhança das respostas referentes aos recursos TIC disponíveis para uso pelos professores, também aqui os valores mais elevados referem-se à internet $(70 \%)$ e computadores $(67 \%)$ e o valor mais baixo ao acesso a tablets (2\%). Na sua globalidade os valores registados respeitantes aos recursos disponíveis para uso dos alunos é inferior aos valores referentes aos recursos disponíveis para os professores.

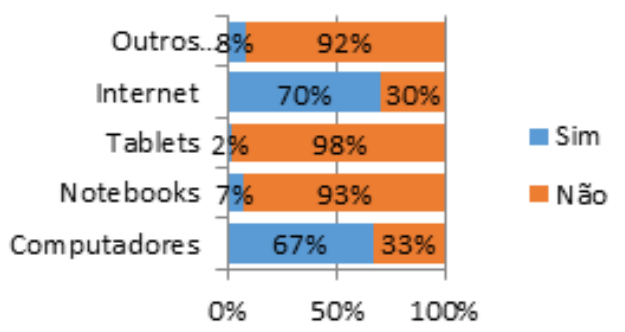

Gráfico 10-Recursos de TIC disponíveis aos alunos nas escolas. 
Os resultados obtidos relativamente aos recursos de TIC utilizados pelos professores com seus alunos encontram-se apresentados no gráfico 11. De forma coerente com os dados anteriores, os recursos mais utilizados são os computadores e a internet.

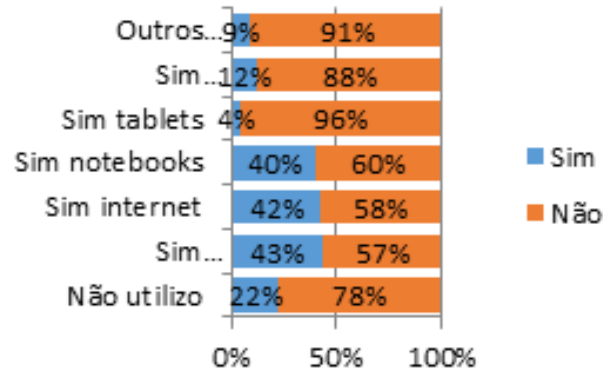

Gráfico 11 - Uso de recursos de TIC utilizados pelos Professores com seus Alunos.

Os resultados obtidos neste estudo relativamente ao uso, pelos professores, de recursos TIC com alunos com NEE encontram-se apresentados no gráfico 12.

Note-se a baixa utilização de recursos TIC com estes alunos, sendo o valor mais elevado, o uso de computadores apontado por $19 \%$ e a existência de $64 \%$ que refere não utilizar (atualmente) nem ter utilizado qualquer recurso TIC com os seus alunos.

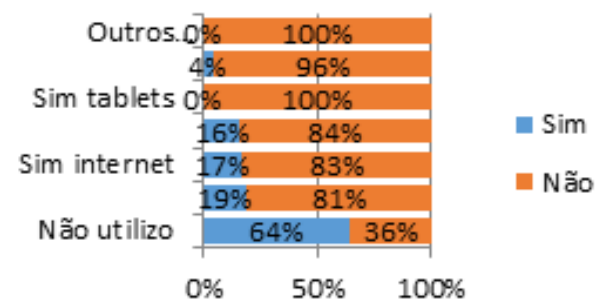

Gráfico 12 - Recursos TIC utilizados pelos professores com seus alunos com NEE.

\section{Síntese e dados e principais conclusões}

$\mathrm{O}$ estudo revelou que dentre os respondentes do questionário da pesquisa $45 \%$ revelou possuir alunos com NEE no ano letivo 2013/2014 no Ensino Médio, sendo que no seu conjunto, os professores inquiridos tiveram nas suas turmas alunos com NEE em pelo menos um dos anos letivos entre 2008/2009 e 2013/2014 de acordo com os dados recolhidos, o que evidencia um elevado índice da prevalência de alunos com NEE na rede pública estadual no municipío de Manaus, fato este que não pode passar despercebido aos gestores das políticas públicas educacionais, no que se refere à implementação de medidas que contemplem uma formação docente para a educação inclusiva. Plestsch (2009) salienta que entre as exigências para a formação docente nos novos rumos que delineiam a educação estão "assumir e saber lidar com a diversidade existente entre os alunos", conforme constam na proposta do MEC para a formação de professores da educação básica.

Relativamente à prevalência dos diversos tipos de NEE em turmas do ensino regular nas escolas em causa, constatou-se que $42 \%$ dos respondentes afirmou possuir alunos com deficiências ligadas ao tipo das "deficiências físicas", $40 \%$ "deficiências intelectuais" e $31 \%$ deficiência auditiva. Plestsch (2009) levanta o fato de que recentes estudos sobre a formação de professores no Brasil revelam que "os professores, de modo geral, não se sentem capacitados para receber um aluno com deficiência, apesar de acreditarem nos méritos da inclusão" (Plestsch, 2009, p.147).

Os resultados relativos à formação dos professores no âmbito das necessidades educativas especiais evidenciaram o despreparo dos professores em lidar com alunos com NEE em sala de aula, uma vez que apenas $11 \%$ dos respondentes afirmou possuir formação acadêmica em NEE. A situação é mais promissora em relação à formação em NEE durante a graduação (54\%) e igualmente preocupante em relação à formação em NEE durante a pós-Graduação.

Em relação à formação dos professores em TIC, $29 \%$ dos respondentes afirmaram que possuem formação para esta área em contraste com os $71 \%$ que não possuem nenhuma formação em TIC. Quando se trata de disciplinas de formação em TIC na graduação, encontramos um equilíbrio entre os que cursaram estas disciplinas (48\%) e os que não cursaram (49\%), enquanto que na pós-graduação encontramos $29 \%$ dos respondentes possuindo formação em TIC contra $68 \%$ não possuindo esse tipo de formação. Os dados referentes às disciplinas de formação de graduação/continuada em TIC e NEE revelaram que apenas 19\% dos professores possui formação nessa área, e uma ínfima minoria (3\%) possui várias formações nessa área. Em geral, os resultados corroboram a assertiva de Santarosa (2012) para quem "a fragilidade da formação docente no âmbito do atendimento do público-alvo da Educação Especial e a incipiente fluência digital dos professores são minimizadas quando a tecnologia é disponibilizada para o aluno" (Santarosa, 2012, p.222). Como evidenciou Santarosa em sua pesquisa em duas cidades onde o PROUCA (Programa Um Computador por Aluno) foi implantado "por meio da mediação proporcionada pelo laptop educacional, processos de autonomia e de protagonismo do aluno com deficiência são efetivamente impulsionados". (Santarosa, 2012, p.222).

Os dados referentes às condições de acesso às TIC em casa revelaram que a maioria dos respondentes têm computador em casa (51\%), notebook (78\%), celular $(67 \%)$ e smartphone $(45 \%)$. Além disso, a grande maioria dos respondentes afirmou possuir acesso à internet (92\%). Estes dados mostram que apesar de não possuir formação específica para as TIC, os professores já as incorporam ao seu cotidiano, o que exige a necessidade de ações por parte dos agentes educativos que contemplem a formação destes profissionais para a incorporação das TIC também em suas práticas pedagógicas.

Os dados referentes às condições de utilização das TIC como recurso didático revelaram que o emprego do datashow prevalece como o recurso mais utilizado entre os respondentes (84\%), seguido do emprego da televisão/vídeos (74\%), notebook (74\%) e livro $(55 \%)$. Entre os recursos TIC disponíveis aos professores na escola, prevalece entre os respondentes o uso da internet (90\%), computadores $(88 \%)$ e notebooks $(38 \%)$. Os 
recursos TIC disponíveis aos alunos, revelados entre os respondentes apontam que a internet é o recurso mais utilizado (70\%), seguido de computadores (67\%) e notebooks $(38 \%)$.

Em relação ao uso dor recursos TIC com alunos encontramos equilíbrio entre computadores (43\%), internet $(42 \%)$ e notebooks $(40 \%)$. Entretanto, o mesmo não pode ser dito em relação ao uso dos recursos TIC pelos professores com seus alunos com NEE. Entre os respondentes, $64 \%$ afirmou que não utiliza, seguido de $19 \%$ que utiliza computadores, $17 \%$ internet e $16 \%$ utiliza notebooks. Sob a ótica de Giroto, Poker, e Omote (2012) compreende-se que entre os respondentes não há o emprego de estratégias diferenciadas de ensino com seus alunos com NEE, mesmo com condições de acessibilidade às TIC por parte da escola, evidenciando a carência de preparo entre os professores para lidar com as TIC, pois apesar de possuirem condições de acesso e uso das mesmas em casa, os mesmos encontram-se despreparados para usá-las no apoio aos alunos com NEE em suas práticas pedagógicas. Giroto, Poker e Omote sumariam: "Para tanto, é preciso investir (...) em uma sólida formação profissional que propicie a competência necessária para o professor refletir, pesquisar e apresentar proposições sobre a prática educativa e sobre novas possibilidades teórico-metodológicas para, consistentemente modificar a realidade" (Giroto, Poker, Omote, 2012, p.20).

Um aspecto importante a ser compreendido na utilização das TIC na educação de alunos com NEE é o papel que esta ocupará nas políticas públicas de formação de professores, uma vez que a simples inserção das TIC na grade curricular dos cursos de licenciatura e pedagogia existentes no país não irá garantir uma prática pedagógica inclusiva de qualidade. É preciso que haja o desenvolvimento de iniciativas quanto ao desenvolvimento de programas que permitam o questionamento deste papel, que consequências irá promover em termos de mudança, de forma a torna-la efetivamente meios de garantir o ensino-aprendizagem de alunos com NEE, de forma que a venha a consolidar-se como ferramenta pedagógica empregada no dia a dia do professor. Hodiernamente, não há praticamente dúvidas a respeito da eficiência do emprego de recursos TIC nas práticas pedagógicas, mas questiona-se que papel que as TIC terão no processo ensino-aprendizagem como aponta Bortolozzo.

A pesquisa sobre a inclusão escolar de alunos com NEE por meio das TIC's na rede pública estadual do município de Manaus representa um campo de investigação que ainda não foi suficientemente desbravado pela comunidade acadêmica, principalmente no que diz respeito às experiências pedagógicas dos docentes, em especificidade os que trabalham no Ensino Médio.

A partir desta perspectiva compreende-se que o emprego das TIC's como prática pedagógica possibilita aos alunos com NEE participar do processo educativo de forma inclusiva, o que em outras situações não seria possível, privando desta forma estes alunos do direito à educação inclusiva, sem barreiras de nenhuma ordem, sejam elas físicas ou conceituais. No entender de Alba (2006), tais barreiras são utilizadas quando "se planeja a educação para alunos "normais", sem entender que o normal é que exista a diversidade; que a normalidade inclui diferentes formas de participar, comunicar-se e aprender, mesmo que essas formas sejam eventuais". (Alba, 2006, p.131).

A busca pela implementação de um currículo que contemple a formação de profissionais da educação que abandonem práticas educativas segregadoras que teimam em se perpetuar em nossas escolas, deve ser uma preocupação constante de todos os administradores das diferentes esferas da educação (o MEC, as secretarias estaduais e municipais de educação) bem como de todos os setores da sociedade civil organizada, pois a bandeira da educação inclusiva tem que ser empunhada e erguida por todos aqueles que desejam uma educação de qualidade e igualitária para todos os nossos alunos, sejam eles deficientes ou não.

\section{Referências Bibliográficas}

Alba, C. (2006). Uma educação sem barreiras tecnológicas. TIC e educação inclusiva. In SANCHO, Juana María; Hernández, Fernando (Org.). Tecnologias para transformar a educação. Porto Alegre: Artmed.

Bortolozzo, A: R. (2008). Banco de dados para o uso das tecnologias de informação e comunicação na prática pedagógica de professores de alunos com necessidades educacionais especiais.; In Ramos, Dimeire Sant'Anna; Ens, Romilda Teodora; Casteleins, Vera Lúcia (Organizadoras). Anais do VIII Congresso Nacional de Educação-EDUCERE [recurso eletrônico]: formação de professores: edição internacional. Curitiba: Champagnat.

Campos, C. M (2010). Gestão escolar e docência. São Paulo: Paulinas.

Giroto, C.RM; Poker, R. B; Omote, S. (2012). Educação especial, formação de professores e o uso das tecnologias de informação e comunicação: a construção de práticas pedagógicas inclusivas. In Giroto, C.RM; Poker, R. B; Omote, S. As tecnologias nas práticas pedagógicas inclusivas. São Paulo: Cultura Acadêmica.

Moran, J. M. (2001). Novas tecnologias e mediação pedagógica. José Manuel Moran, Marcos T. Masetto, Marilda Aparecida Behrens. Campinas: Papirus.

Pletsch, M. D. (2009). A formação de professores para a educação inclusiva: legislação, diretrizes políticas e resultados de pesquisas. Educar em Revista, (33), 143-156. Disponível em:

$<$ http://dx.doi.org/10.1590/S010440602009000100010>. Acesso em 17/09/14.

Santarosa, L M. C. (1997). "Escola virtual" para a educação especial: ambientes de aprendizagem telemáticos cooperativos como alternativa de desenvolvimento. Revista de Informática Educativa, Bogotá, v. 10, n. 1, p. 115-138.

Santarosa, L M. C. (2012). PROUCA e o processo de inclusão escolar e sociodigital de alunos com deficiências. In Sampaio, F.F.; Elia, M.F. (Orgs.). 
(2012). Projeto um computador por aluno: pesquisas e perspectivas.

UNESCO. (2013). Opening new avenues for empowerment: ICTs to acess information and knowledge for persons with disabilities. Paris: UNESCO.

Valle, L. (2013). Entrevista Educação digital e inclusão social. Disponível em: <http://www.grupoa.com.br/blogA. Acesso em: 02 jan. 2014. 